\title{
Study on the Control of Anti-lock Brake System based on Finite State Machine
}

\author{
LI Bing-lin,WAN Mao-song \\ College of Automobile and Traffic Engineering, Nanjing Forestry University, Nanjing, China \\ E-mail: Ibljdz@alinyun.com
}

Keywords: Anti-lock Brake System, Modeling, Co-simulation, finite-state machine

\begin{abstract}
The vehicle braking process and working principle of Anti-lock Brake System (ABS) are analyzed. According to the nonlinear ABS brake model and time-varying characteristics, a more accurate ABS hydraulic numerical model is established. Combined with Matlab software, a single wheel vehicle ABS dynamics model is established, which makes the control of vehicle ABS is more close to reality. The ABS hydraulic brake control system is realized by using control strategy based on PID control and finite-state machine method. Through the co-simulation of AMESim and Simulink, the results show that the method could effectively control of ABS, and the simulation process can study the influence of each parameter of hydraulic system, but also it can provide theoretical guidance for the setup of ABS experiment platform, which can shorten the system's development period, and reduce the experiment cost.
\end{abstract}

\section{Introduction}

ABS is a nonlinear and time-varying system; so it is difficult to establish complete and accurate braking model. The components and parameters of hydraulic system are critical to the whole system performance of static and dynamic characteristics. The ABS hydraulic system model often uses the transfer function, state space method, but these methods of modeling usually simplifies the hydraulic system by experience, or uses one or two order model instead, ignoring the delay nonlinear factors and the pressure transmitting of electromagnetic valve spring, which make the simulation results deviate with the actual situation. Jin modeled electronic hydraulic brake system, and identified the parameters by used linear regression theory, but the modeling rarely considered the inherent characteristics of the hydraulic system [1]. Most of the current relevant research for the control of the ABS are based on the assumption that the braking torque can be continuous and precise adjustment, which is inconsistent with the actual situation [2][3]. In order to discuss the issue conveniently, the author Liu took the braking system model into two parts. One is hydraulic transmission model, and the other is brake torque model. He simplified the hydraulic transmission system as an electronic valve and an integral part, which is the real difference between the two case [4]. In order to discuss these problems, the simulation of combining theoretical with numerical to model was introduced in the paper. As for ABS the nonlinear time-varying characteristics, the paper models ABS main components and the vehicle, which comprised a braking system dynamic simulation platform. The AMESim is used to model for hydraulic system and the Simulink is used to study the ABS control strategy based on the finite state machine theory. The simulation method has the advantage that can be verified and improved on the control strategy, providing a theoretical basis for the ABS the construction of the control system experimental platform.

\section{The dynamic model of ABS}

In order to make things easier, not to consider the air resistance, the wheel rolling resistance , acceleration resistance and other factors, only to consider the vehicle longitudinal motion and the rotation of the wheels, two degree of freedom model of single wheel can be acquired. The single wheel vehicle model is shown in Figure 1. 


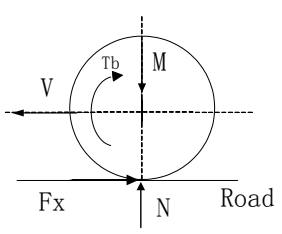

Figure 1 a single wheel vehicle model diagram

Therefore, the motion equation of vehicle can be expressed by using the equation (1):

$$
M \dot{V}=-F_{x}
$$

Where, $M$ is automotive quality; $V$ is the velocity of the vehicle; $F_{x}$ is the ground braking force. The motion equation and longitudinal friction of wheel for Figure 1 can be written as follows respectively.

$$
\begin{gathered}
I \dot{\omega}=F_{x} r-T_{b}=T_{g}-T_{b} \\
F_{x}=\mu N
\end{gathered}
$$

Where, $I$ is wheel moment of inertia; $\omega$ is the wheel angular velocity; $r$ is the wheel rolling radius; $T_{b}$ is braking torque; $T_{g}$ is braking torque between the tire and the ground; $\mu$ is adhesion coefficient; $N$ is normal counter force of the wheels on the ground. The slip ratio equation is defined as follow.

$$
S=1-\frac{\omega}{V / r}
$$

Where, $S$ is slip ratio of wheel.

\section{Modeling of ABS hydraulic system based on AMESim}

AMESim is a software containing dynamic analysis model of hydraulic and mechanical system, which can be used to model vehicle dynamics system, hydraulic components system and brake system. Combined control system moduel of Simulink with AMESim during the process of simulation, the co-simulation function in braking system is achieved. ABS hydraulic system model is mainly composed of the brake master cylinder, the hydraulic regulation system model , electronic control unit model and the brake wheel cylinder model.

\section{A. the Brake Master Cylinder Model}

According to the traffic regulations, ensure the running safety of vehicle,the brake system of the modern automobile have adopted dual circuit brake system,using a serial double chamber master cylinder. The paper adopts dual circuit brake system series dual chamber brake master cylinder model, the model is shown in Figure 2.

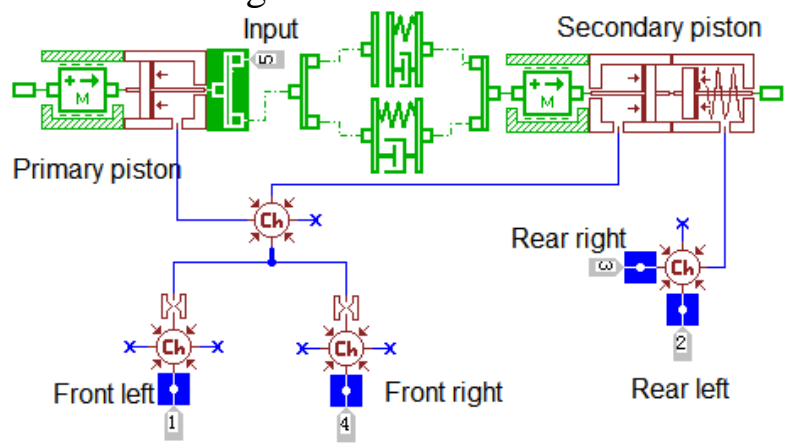

Figure 2 brake master cylinder model

\section{B. the Wheel Cylinder Model}

Caliper disc brake is analyzed in the paper. During the process of the anti-lock braking, the force and motion state of the wheelcylinder piston are constantly changed due to the brake pressure changing repeatedly. So, when modeling wheel cylinder piston, the effect of the dynamic characteristics of the mathematics model should be considered, as shown in equation (5). 


$$
\left\{\begin{array}{l}
m \frac{d^{2} x}{d t^{2}}=-P S+C_{e q} \frac{d x}{d t}+K\left(x_{0}+x\right) \\
x S=\int_{0}^{t} Q d t
\end{array}\right.
$$

According to the structure of the wheel cylinder , the established model is shown in Figure 3.

Caliper

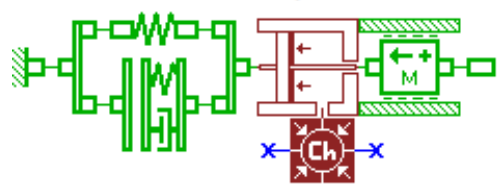

Figure 3 Wheel Cylinder Model

\section{The High-Speed Electromagnetic Valve Model ${ }^{[5][6]}$}

Using two order delay block to describe the control model between the control signal and the solenoid valve, which represent the response characteristics of the solenoid valve. The transfer function of model is shown in equation (6) .

$$
G(s)=\frac{K e^{-\tau s} w_{n}^{2}}{s^{2}+2 \xi w_{n} s+w^{2} n}
$$

Where, $K$ is the gain; $\tau$ is the time delay; $w_{n}$ is the solenoid valve natural frequency; $\xi$ is solenoid valve damping ratio.

The flow characteristics of solenoid valve is related to the valve port shape, the brake fluid density, pressure difference between the valve port, valve opening flow area, the brake fluid dynamic viscosity and other factors. The mathematical model is shown as follow:

$$
Q=C_{q} A \sqrt{\frac{2|\Delta P|}{\rho}} \tanh \left(\frac{8 A}{\chi \eta_{0} \lambda_{c}} \sqrt{\frac{2|\Delta P|}{\rho}}\right)
$$

where, $Q$ is the brake fluid flow; $C_{q}$ is the maximumflow coefficient; $\rho$ is the brake fluid density; $\Delta P$ is the pressure difference at both end of port; $A$ is the throttle orifice cross sectional area; $\lambda_{c}$ is the brake fluid flow Reynolds number; $\chi$ is the throttle orifice of wetted perimeter length; $\eta_{0}$ is the brake fluid dynamic viscosity.

\section{ABS Hydraulic System of Single Wheel Vehicle Model}

According to the principle of ABS, the hydraulic system of ABS single wheel vehicle model can be established in the AMESim, as shown in Figure 4.

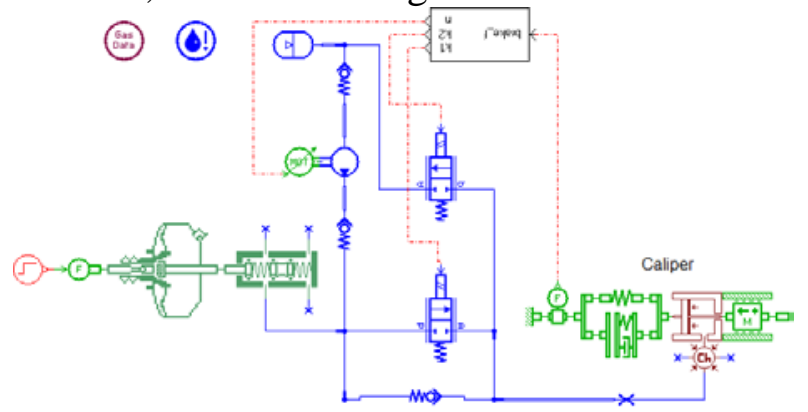

Figure 4 ABS hydraulic simulation model of single wheel vehicle

The system include main vacuum booster, brake master cylinder, brake wheel cylinder, pressure control valve etc.. The Figure 4 also shows the co-simulation interface between the AMESim and Simulink, which can realize the data exchange between AMESim and control module of Simulink. In the figure 4, K1 is the oil inlet valve control signal; K2 is the oil return valve control signal; $n$ is the pump motor control signal; the output of hydraulic system model are vehicle braking force.

The hydraulic system we discussed in the paper reference to the actual existing hydraulic system of ABS used in the vehicle. Some of parameters of system refer to it too [7], as shown in Table 1. 
Table 1: related parameters of hydraulic system:

\begin{tabular}{l|c}
\hline Average power viscosity of brake fluid: $\eta_{0}$ & $42.5 \mathrm{~mm}^{2} / \mathrm{s}$ \\
\hline Electromagnetic valve orifice aperture & $0.6 \mathrm{~mm}$ \\
\hline The density of brake fluid: $\rho$ & $850 \mathrm{~kg} / \mathrm{m}^{3}$ \\
\hline The maximum flow coefficient $: C_{q}$ & 0.7 \\
\hline Reynolds number: $\lambda_{c}$ & 100 \\
\hline The capacity parameter accumulator $: V_{0}$ & $0.25 \mathrm{~L}$ \\
\hline The maximum working pressure $: P_{\max }$ & $16 \mathrm{Mpa}$ \\
\hline The velocity of pump motor & $500 \mathrm{r} / \mathrm{min}$ \\
\hline Pump displacement & $0.1 \mathrm{~mL} / \mathrm{r}$ \\
\hline
\end{tabular}

\section{The control strategy implementation}

The ABS model of the hydraulic system and the vehicle model and its control strategy are established in AMESim and MATLAB/Simulink respectively.

\section{E. A Single Wheel Vehicle Model}

According to the describing mentioned above, the dynamics model of single wheel ABS is established in Simulink as shown in Figure 5.

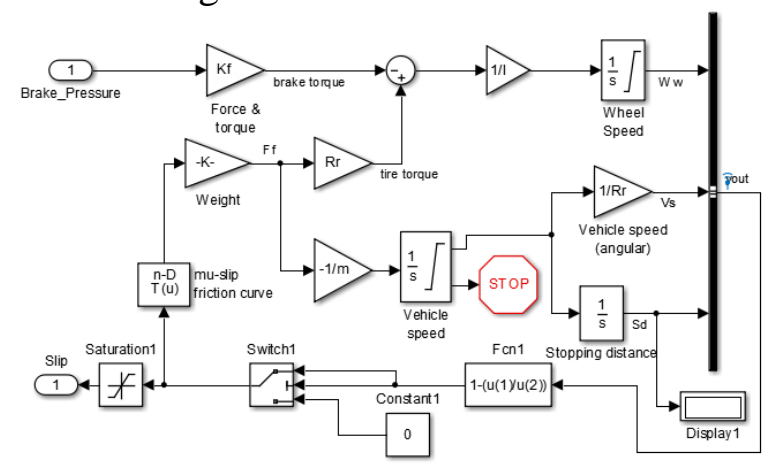

Figure 5 single wheel dynamic model of ABS

\section{F. $\quad$ the Finite-State Machine Control}

The finite-state machine (FSM) is a mathematical model of computation used to design both computer programs and sequential logic circuits. According to the theory of finite-state machine, conditions of one state transition to another state can be designed; and each pair of convertible state is designed to state migration events, so as to construct the state transition diagram. In the process of braking, the brake events of pressure booster, pressure holding, pressure decreasing are switched by used the finite state machine theory. The finite-state machine control flow chart is shown in Figure 6.

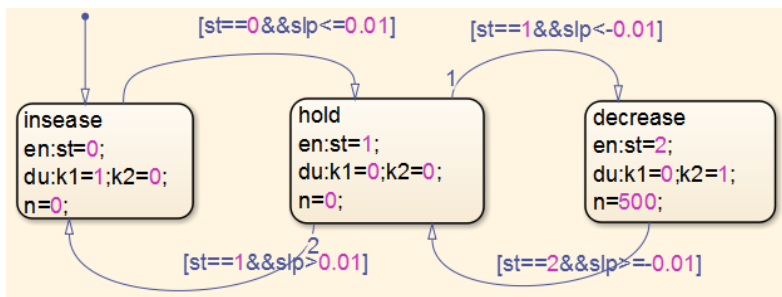

Figure 6 Stateflow state of control flow graph

When the deviation value of the input signal meet the transfer conditions, the event will transfer to the next logical state. In this way, the pressure of hydraulic system is among in the three continuous work state of increasing, keeping or decreasing. Thereby, regulating the brake force to adjust the system reaches the expected value of slip ratio of wheel. The detail of control strategy of Stateflow process is shown in Figure 6. 


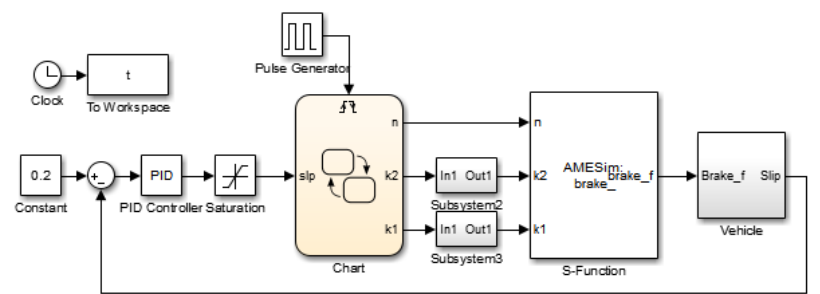

Fig 7 Simulink simulation model of single wheel vehicle ABS

Figure 7 is a Simulink simulation model graph of single wheel vehicle ABS. Where, using PID controller to control the deviation between actual slip ratio and reference slip ratio, and then the output decide to the action of solenoid valve through the finite-state machine.

\section{The results of simulation analysis}

In the simulation, brake force of brake pedal is given at the beginning; the value is $400 \mathrm{~N}$. After that the master cylinder piston pressure is shown in Figure 8.

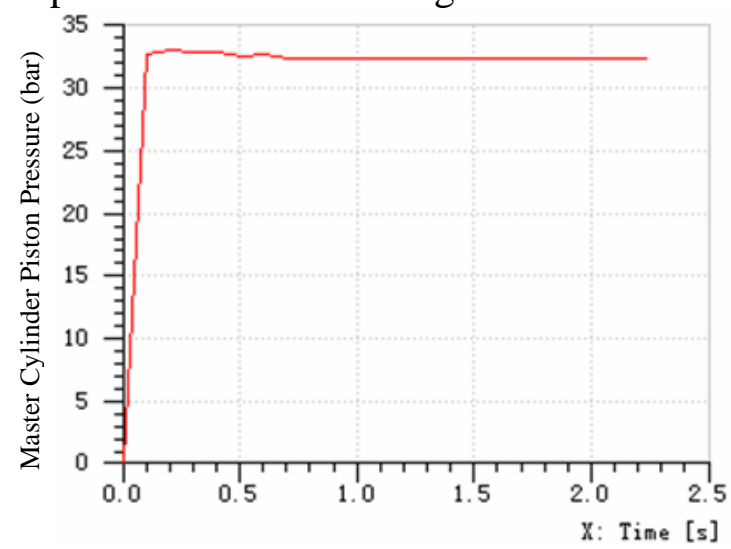

Figure 8 the main cylinder piston pressure

The initial parameters of simulation are given as follow. The initial velocity is $18 \mathrm{~m} / \mathrm{s}$; wheel's moment of inertia is $2.2 \mathrm{~kg} \cdot \mathrm{m}^{2}$; the $1 / 4$ quality of the vehicle $300 \mathrm{~kg}$; wheel radius is $0.3 \mathrm{~m}$. The road simulation is carried out; and the changing curves of slip ratio, wheel velocity, vehicle velocity are achieved, as shown in Figure 9, Figure 10 respectively. It can be seen from the two figures, the system has reached the expected value of the optimal slip ratio of 0.2 , at the same time, and the wheel velocity is superior to the tracking velocity, to achieve the ideal state of control.

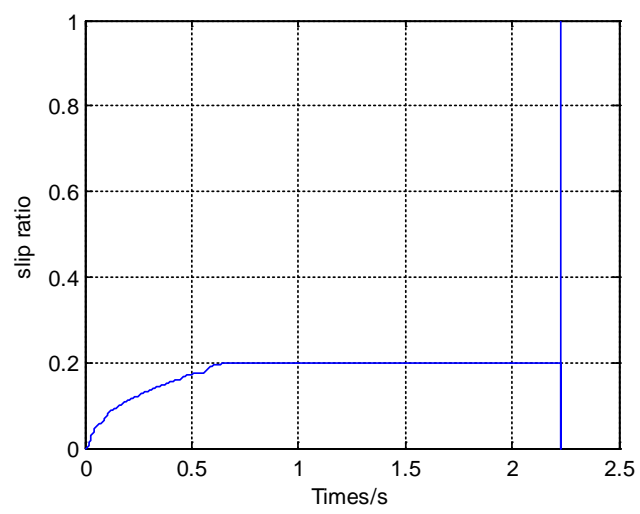

Figure9 Simulation results of the slip ratio 


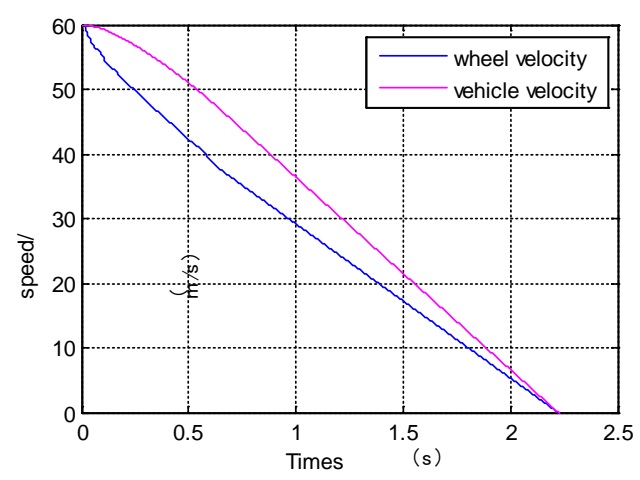

Fig. 10 Simulation results of between wheel velocity and vehicle velocity

It can be seen from the Figure 11 the braking distance is $21.77 \mathrm{~m}$. It took $2.225 \mathrm{~s}$ braking time to stop the vehicle. As shown in figure 11.

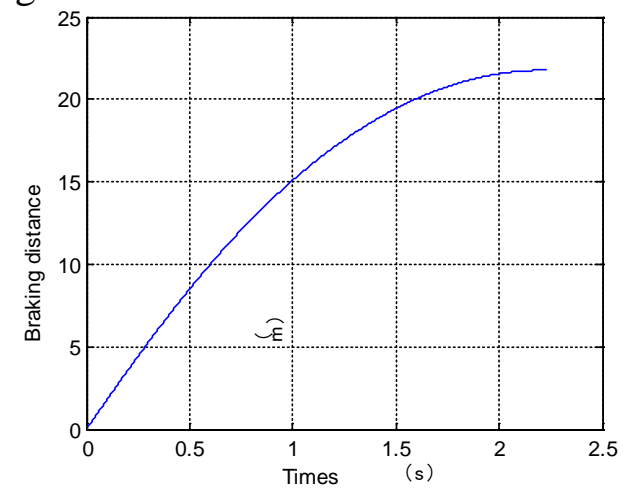

Figure 11 Simulation results of braking distance

The simulation result of brake pressure is shown in Figure 12.

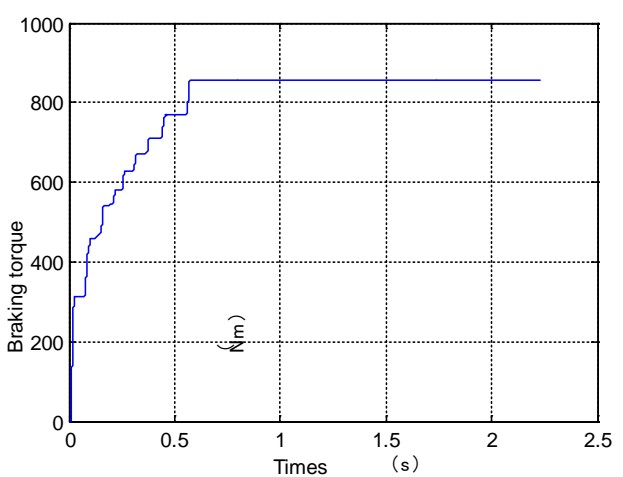

Figure 12 Simulation results of brake torque

\section{Conclusion}

According to the nonlinear ABS braking model and time-varying characteristics, the high accuracy hydraulic system model of single wheel ABS is established by AMESim; and combining with the Matlab software, the single wheel vehicle dynamic model of ABS is established. By cosimulation, the control of the ABS is realized. The simulation results show that ABS system model established in this paper is effective and practical. The simulation method has good feasibility and practicability. And the parameters in the simulation system can be changed according to the specific models of the change, to facilitate the design of ABS system and the optimization of system parameters, to save experimental cost. As a reference, it has significance to study other automobile system. 


\section{Acknowledgement}

The authors would like to thank the reviewers for their comments on the manuscript improvement. Thanks to funding of Jiangsu province college fund.

\section{References}

[1] Jin Zhilin, Guo Lishu et al. Journal of automobile, electric hydraulicbraking system dynamic performance analysis and experimental study on the[J]. of mechanical engineering, 2012, 48 (12), 127-132.

[2] JOHANSEN T A, PETERSEN I, KALKKUHL J, et al. Gain-scheduled wheel slip control in automotive brake systems $[\mathrm{J}]$. IEEE Transaction on Control and System Technology, 2003, 11(6) : 799-811.

[3] TANELLI M, ASTOLFI A, SAVARESI S. Robust non-linear output feedback control for brake-by-wire controlsystems $[\mathrm{J}]$. Automatica, 2008, 44(4) : $1078-1087$.

[4] Liu Zhiqiang, Tang Zhonggang ABS particle swarm optimization simulation of PID slip rate based on control [J]. Journal of Chongqing Jiaotong University(NATURAL SCIENCE EDITION), 2013, 32 (5): 1096-1010.

[5] Su Ming, Chen Rankin. Electromagnetic high-speed on-off valve AMESimstatic and dynamic characteristics of [J]. hydraulic and pneumatic based,2010 (2): 68 71.

[6] Jiang Lingling, Zhang Junjun. AMESim and Matlab/Simulink co simulationinterface and Application Research Based on [J]. machine tool \& hydraulics,2008,36 (1), 148 149.

[7] Xuele Qi, J ian Song, HuiyiWang1 Influence of Hydraulic ABS Parameters on Response Time and Braking Effect[C]. SAE 2005-01-15901 